\title{
Integration of urban and rural minimum living security system obstacle of realistic considerations under the background of new household registration system reform
}

\author{
Ziqianhong Wan \\ North China Electric Power University, Baoding, China \\ yanda325221@163.com
}

Keywords: the reform of the household registration system; urban and rural living security system; urban-rural integration; obstruction.

\begin{abstract}
Since July 30, 2014, "To further promote the reform of the household registration system view" has released, the current discussion about the household registration system focused more on urban and rural subsistence allowances system as the main content of the basic public service system. I try to pass to analyze the current exhibit of Chinese provinces and cities in the context of the reform of the household registration system guaranteeing the common problems in the urban-rural integration process, I conclude that one is balancing a household registration system between urban and rural service to promote them becoming effective protection of the rights and interests of the citizens of the community benign system, the other is to hope to provide reference for the construction of urban and rural low for system integration and realize the goal of the equalization of basic public services in urban and rural areas.
\end{abstract}

\section{Introduction}

A distinct feature of the traditional household registration system is that it comes with the interests of the distribution function, the embodiment of the registered permanent residence is not only an identity, and it is for resources and interest shall enjoy the right to confirm, the household registration and therefore carrying too much additional functions, employment, education, housing, health care, and many of the rights and interests of citizens [1]. On July 30, 2014, "on further promote the reform of household registration system of opinion" issued dismantled the urban-rural binary partition the administrative barriers and how to gradually stripped and are tied to the household registration system of subsistence allowances and benefits, this is one for the moment.

In some perspective, a new round of reform of household registration is to our country the systematic reform of the household registration system, the urban and rural identity based pattern of urban and rural subsistence allowances system could lead to disruptive impact system. The contents related to the opinions of comprehensive, but for urban and rural minimum living security system, its direct impact has the following four aspects(hukou registration system orderly urbanization, cancellation, a new residence permit with the corresponding public services, perfect with low system as the core of social assistance system).Here, the author tries from the reform of household registration system to four content difference a qualitative level, to explore the reform of household registration system the impact of the change to the existing urban and rural subsistence allowances system.

\section{The household register difference registration cancelled}

"Opinion", "cancel agricultural and non-agricultural household register to distinguish and variations of blue print account such as account types, unified registration for residents registered permanent residence, reflect the hukou system of the population registration and management function".

At present, China's urban minimum living security system, set up in the "dual household registration management, based on the urban and rural subsistence allowances of the object 
recognition is in accordance with the regulations on the subsistence allowances for urban residents of the state council provisions, such as only qualify for the local towns, the permanent residence, agriculture account or account is beyond the scope of the local is not in the lowest life guarantee range. Now, now that we have to cancel the "agricultural" and "non-agricultural hukou" distinction, household basis, the lowest life guarantee administration organ in the city what to distinguish the basis of urban low-income residents and rural low-income residents?

\section{A new round of orderly urbanization}

"Opinion" is put forward, and guide the agricultural population to cities in an orderly way, and to promote urbanization, especially the "orderly release medium cities limit, let go of small town and city in comprehensive restrictions".

First, a new round of urbanization is facing a big trouble, is to realize the fiscal expenditure equal public services need to local government pressure. Settled in condition of small and medium-sized cities with ease, a large number of rural population, or some live in the town of landless peasants should inevitably into the category of urban residents, urban low coverage must expand, the lowest life guarantee money greatly increase the demand for funds. Not only the central and local governments at various levels of low budget is questionable, can guarantee the low actual demand from a simple and not very accurate calculation, for government investment spending, urbanization is essentially to solve related to the account of basic public services. Here mainly includes based on the urban minimum living guarantee, including health care, social security system. If you look away, in the future 20 years, 600 million new citizens, an average 25 million people a year, spending on average 80000-100000 yuan. Once became a citizen, so, the government each year of new urbanization investment in 2 trillion yuan of above. Without considering natural growth and calculate each year one-time spending only under the premise of initial density is as follows: the urban and rural low-income standards is generally $20 \%$ of urban residents per capita disposable income and rural per capita net income of more than $25 \%$, according to urban residents per capita income totaled 26959 yuan, per capita net income of rural residents 7917 yuan, after all the citizens, per capita spending 3400 yuan more [2].

\section{Residence and public services}

"Opinion" is put forward and set up the system of residence permit, and demanding "on the carrier of residence permit, establish and improve the link and fixed number of year of the living conditions of basic public service system", "such as continuous and attend social insurance years of living conditions, gradually enjoy equal social relief and so on with the local population of rights".

Legislative affairs office of the state council at the end of 2014 issued a "residence permit management regulations (draft)", the "draft" puts forward nine basic public services on residence permit holders, according to the draft of the state council, residence permit will be and the people enjoy the public service links up, education, health care, housing, cars, these should be addressed by the residence permit system, realize the equal basic public services. "Accordingly, residence permit is not purely a household registration management measures, it is associated and enjoy the public service, residence permit to hold also enjoys one of the access conditions becomes low.

Only from the point of view on the above content, if low applicants would be able to apply for residence permit to the city, then residence permit holders can enjoy the treatment has been basically is almost the same with the local population, nature also can apply for subsistence allowances. Residence permit, in fact, not only there are differences, registered permanent residence this getting on the name and its hidden behind the application condition and its transition is the real difficulty and problem. Application conditions, for example, there are still a lot of "glass door". As in "draft" is put forward: citizens leave, constant registered permanent address locus to other districts under the jurisdiction of city living for more than six months, as long as there is stable employment, stable residence, conforms to the condition of continuous study, one of the, can apply for residence permit in 
accordance with the regulations. But what exactly is stable employment, what circumstances and have stable residence, there are larger explanation of flexibility. In addition, the measures for the administration of the residence permit final regulations have not been released to the public.

Moreover, the meaning of equal basic public services mainly include three aspects, one is a relative balance between area, the 12th five-year plan outline is put forward, and gradually achieve equal basic public services, different regions of the key is to improve the quality of basic public services is relatively backward region; Second, the relative balance between rural and urban areas, the key is to improve the level of basic public services in rural areas; Between urban residents and the residents of relative balance, the key is the hukou residents reasonable share of local urban basic public services. But due to the current situation of the development of social economy, the rural population base is big, the living standards of urban and rural gap is too big to the influence of the real conditions, such as to achieve the three relative balance, may need a relatively long period of time.

\section{5. "Perfect with low system as the core of social assistance system, realize urban and rural social assistance plan as a whole development"}

"Opinion", "Perfect with low system as the core of social assistance system, realize urban and rural social assistance plan as a whole development", directly to low as the core of the social relief system reform put forward the request, must take assistance between urban and rural areas as a whole view of the development of the low system reform. So, in terms of the system of subsistence allowances for urban and rural areas as a whole, what plan as a whole, how to implement path as a whole, and a series of problems, are to be answered [3].

Due to transition to a specific political, economic, and social background, combined with the urban and rural segmentation limit of thinking, at the beginning of the minimum living security system of our country, it has obvious characteristics of urban-rural division, mainly embodied in the implementation of different low standards and subsidy level, at the same time, the urban and rural subsistence allowances system in such aspects as management operation, financing source and structure also exist significant differences, this is a legacy of the minimum living security system. But as the systemic reform of China's household registration system of the new reform of household registration, proposed gradually unified registration of registered permanent residence, implement the residence permit, open and orderly in policy, all low system brings the new impact of urban-rural division, forming a new challenge.

Author in this article only from qualitative level to evaluate the impact of the change new homes for low-income urban and rural areas as a whole. In new homes to quantitative level assessment of the impact of the three areas, namely, the flow of population areas, agricultural population urbanization transfer stressed areas and poor areas at the grass-roots level, under the background of the new door to advance the low-income urban and rural areas as a whole may impact; And new families to other impact on urban and rural subsistence allowances system. The author is not involved, content is not detailed, comprehensive enough.

\section{References}

[1] Gong Weicai, "five in one": the basic structure of the integration of urban and rural subsistence allowances system [J]. Socialism with Chinese Characteristics, 2010,01: 69-73.

[2] Guo Jianmei, Liu Xiaohong, Liu Tongxiang , design and improvement about the integration of urban and rural low operating mechanism [J]. Xinjiang reclamation economy, 2011,04: 50-53.

[3] Xu Qingzhao, Chinese urban and rural low system according to the present stage of convergence problems [J]. Qilu Journal, 2011,04: 107-110. 